\title{
INFLUÊNCIA DA ATIVIDADE MINERADORA NA DINÂMICA DA PAISAGEM: REFLEXÕES TEÓRICAS
}

\author{
Influence of mining activity on landscape dynamics: theoretical reflections \\ Influencia de la actividad minera en la dinámica del paisaje: reflexiones teóricas
}

Manara Teles Santos Matos ${ }^{1}$ http://orcid.org/0000-0002-7645-3423

Meirilane Rodrigues Maia² http://orcid.org/0000-0001-8757-0601

\footnotetext{
${ }^{1}$ Mestranda em Geografia (PPGeo/UESB), membro do Grupo de Pesquisa Análise Ambiental Planejamento e Gestão Territórial (APLAGET), credenciado ao CNPq, Brasil. email - manarateles@outlook.com.

${ }^{2}$ Professora Adjunta do Departamento de Gografia e do Programa de Pós-graduação (PPGEo) da Universidade Estadual do Sudoete da Bahia

- UESB- Brasil, email meire.rmaia@gmail.com
}

\begin{abstract}
Resumo
O presente artigo tem como objetivo discutir a dinâmica da paisagem minerada em Vitória da Conquista-BA. Cuja discussão foi desenvolvida a partir de reflexões teóricas acerca do espaço, paisagem e natureza sob a perspectiva socioambiental. Os seguintes autores foram utilizados como aporte teórico para o desenvolvimento desse trabalho: Bertrand (1972), Sotchava (1963), Cosgrove (2002), Santos (1988) e Smith (1988). Nesse sentido, a paisagem é processo resultante da relação sociedade-natureza, pois é marcada pelos processos físicos, sociais e históricos que a fizeram existir. A mineração envolve processos naturais, econômicos, políticos e sociais; é permeada de diversos interesses por conta dos diferentes sujeitos sociais enredados, os quais terão percepções diversificadas acerca dos aspectos positivos e/ou negativos ocasionados pela exploração de bens minerais, o que influencia diretamente na dinâmica da paisagem. A visão excludente da relação sociedade-natureza, a coloca como fonte de recursos para sociedade a fim de atender suas demandas.
\end{abstract}

Palavras-chave: Paisagem. Natureza. Mineração.

\begin{abstract}
The present article aims to discuss the dynamics of the mining landscape in Vitória da Conquista-BA. Whose discussion was developed from theoretical reflections about space, landscape and nature from a socioenvironmental perspective. The following authors were used as theoretical contribution to the development of this work: Bertrand (1972), Sotchava (1963), Cosgrove (2002), Santos (1988) and Smith (1988). In this sense, the landscape is a result of the relationship between society and nature, as it is marked by the physical, social and historical processes that made it exist. Mining involves natural, economic, political and social processes; is permeated by diverse interests on account of the different entangled social subjects, who will have diverse perceptions about the positive and / or negative aspects occasioned by the exploration of mineral goods, which directly influence the dynamics of the landscape. The exclusionary view of the societynature relationship places it as a source of resources for society in order to meet its demands.
\end{abstract}

Keywords: Landscape. Nature. Mining. 


\section{Resumen}

El presente artículo tiene como objetivo discutir la dinámica del paisaje minado en Vitória da Conquista-BA. Cuya discusión fue desarrollada a partir de reflexiones teóricas acerca del espacio, paisaje y naturaleza bajo la perspectiva socioambiental. Los siguientes autores fueron utilizados como aporte teórico para el desarrollo de ese trabajo: Bertrand (1972), Sotchava (1963), Cosgrove (2002), Santos (1988) y Smith (1988). En ese sentido, el paisaje es proceso resultante de la relación sociedad-naturaleza, pues está marcada por los procesos físicos, sociales e históricos que la hicieron existir. La minería involucra procesos naturales, económicos, políticos y sociales; es permeada de diversos intereses por cuenta de los diferentes sujetos sociales enredados, los cuales tendrán percepciones diversificadas acerca de los aspectos positivos y / o negativos ocasionados por la explotación de bienes minerales, lo que influye directamente en la dinámica del paisaje. La visión excluyente de la relación sociedad-naturaleza, la coloca como fuente de recursos para la sociedad a fin de atender sus demandas.

Palabras clave: Paisaje. Naturaleza. La minería.

Recebido em: 12 /09/2018

Aceito para publicação em: 19/12/2018

\section{Introdução}

A paisagem é processo resultante da relação sociedade-natureza, a qual oferece recursos que são transformados pela sociedade a fim de atender suas demandas. Nesse sentido, o homem em uma sociedade estratificada refletirá diferentes apreensões da realidade, especificamente no que diz respeito às preocupações com a natureza, uma vez que alguns sujeitos sociais podem percebê-la como amenidade: benefícios infindáveis de domínio humano, enquanto outros perceberão essa forma de apreensão como um problema. Assim, são desencadeados conflitos por envolverem as diferenças de interesses da sociedade em relação a natureza, por conta da compreensão dicotômica entre ambas.

Os conflitos decorrentes dessa relação se materializam na paisagem e permeiam a ciência de objetos de estudo e pesquisa a fim de esclarecer a realidade apresentada e vivida. No que tange aos entraves que envolvem a natureza, a busca pela explicativa dos fenômenos deve ser compreendida pela perspectiva socioambiental, pois questões ambientais resultam de reveses sociais, cujas contradições são materializadas na paisagem.

A exploração mineral se constitui como importante atividade econômica, cujos produtos movimentam outras indústrias de processamento. Quase todas as coisas utilizadas no 
cotidiano da sociedade têm elementos minerais, por isso, dessa tividade decorrem proveitos sociais e conflitos socioambientais. Uma vez que envolve processos naturais, econômicos, políticos e sociais; é permeada de diversos interesses por conta dos diferentes sujeitos sociais enredados, os quais terão percepções diversificadas acerca dos aspectos positivos e/ou negativos ocasionados pela exploração de bens minerais.

Nessa perspectiva, esse trabalho tem como objetivo discutir, com base na Teoria Sistêmica, a dinâmica da paisagem minerada em Vitória da Conquista. Para isso, foram realizados levantamentos bibliográficos e revisão de literatura específica. Para os quais, a contribuição de Christofoletti (1990), Sotchava (1963) e Bertalanffy (2015) foram relevantes para a compreensão da Teoria Sistêmica; Santos (1988) e (2014), Bertrand (1972) e Cosgrove (2002) para a discussão da categoria de análise geográfica paisagem; Bernardes e Ferreira (2005) para compreensão da relação sociedade natureza e Smith (1988) para compreensão de natureza.

Esse trabalho é resultado de parte da discussão desenvolvida na dissertação de mestrado submetida ao Programa de Pós-graduação em Geografia da Universidade Estadual do Sudoeste da Bahia (PPGeo/UESB).

\section{Espaço e paisagem na abordagem sistêmica}

O espaço, e os seus processos produtivos atrelados ao desenvolvimento da sociedade, não se constitui como um palco estático onde as relações sociedade-natureza acontecem e materializam suas produções e reproduções. Segundo Harvey (1980), “a compreensão do espaço em toda sua complexidade depende de uma apreciação dos processos sociais" (HARVEY, 1980, p. 26), como reitera Lefebvre (2000) "o espaço social é um produto social” (LEFEBVRE, 2000, p. 55), resultado das ações da relação sociedade-natureza ao longo do tempo. Como produto social, o espaço é dotado de conflitos, por envolver diferentes sujeitos sociais com interesses diversos, nesse ininterrupto processo de produção-reprodução.

Por isso, Santos (1988, p. 04) afirma que "falar sobre o espaço é muito pouco, se não buscamos definí-lo à luz da história concreta. Falar simplesmente do espaço, sem oferecer categorias de análise é também insuficiente". Ou seja, pensar o espaço por ele mesmo não dá conta de compreender a dimensão desse conceito, uma vez que, é construído historicamente pela sociedade e suas relações. Santos (1988, p. 10) acrescenta que "o problema é encontrar as categorias de análise que nos permitem o seu conhecimento sistemático, isto é, a possibilidade de propor uma análise e uma síntese cujos elementos constituintes sejam os mesmos.” 
Assim, ao estudar uma realidade no espaço geográfico, o pesquisador deverá buscar a categoria de análise que melhor lhe permita a compreensão da realidade, bem como apreciação dos processos e elementos que constituem o espaço em constante transformação pela sociedade. Santos (1988) propõe a distinção entre espaço e paisagem, e acrescenta que a última é um elemento fundamental para a compreensão do primeiro; dessa forma, ao tomar por base o seu entendimento sobre a importância das categorias de análise para compreensão do conceito de espaço, é que essa pesquisa se pauta no estudo da paisagem, o que viabiliza a compreensão da produção do espaço geográfico na exploração mineral de agregados para construção civil.

Diante da distinção dos conceitos de espaço e paisagem, Santos (1988) define espaço da seguinte maneira:

O espaço não é nem uma coisa, nem um sistema de coisas, senão uma realidade relacional: coisas e relações juntas. Eis por que sua definição não pode ser encontrada senão em relação a outras realidades: a natureza e a sociedade, mediatizadas pelo trabalho. Não é o espaço, portanto, como nas definições clássicas de geografia, o resultado de uma interação entre $o$ homem e a natureza bruta, nem sequer um amálgama formado pela sociedade de hoje e o meio ambiente. $\mathrm{O}$ espaço deve ser considerado com um conjunto indissociável de que participam, de um lado, certo arranjo de objetos geográficos, objetos naturais e objetos sociais, e, de outro, a vida que os preenche e os anima, seja a sociedade em movimento. O conteúdo (da sociedade) não é independente, da forma (os objetos geográficos), e cada forma encerra uma fração do conteúdo. O espaço, por conseguinte, é isto: um conjunto de formas contendo cada qual frações da sociedade em movimento. As formas, pois têm um papel na realização social (SANTOS, 1988, p. 10).

Cada parte do espaço geográfico e da paisagem contém recortes da dinâmica da sociedade: de modo que, ao analisarmos a exploração mineral de agregados para construção civil é notável a existência de frações da sociedade em movimento relacionada à forma, isto é, aos objetos geográficos daquela paisagem. O que mostra a existência, na realidade, do conceito teórico de espaço em locais de exploração mineral, e a consequente produção espacial nessas áreas. Ao definir espaço, o autor o compreende como um conjunto de objetos geográficos, naturais e sociais envolvidos pela dinamicidade das relações sociais, ou seja, "um conjunto indissociável de sistemas de objetos e de sistemas de ações" (SANTOS, 2014, p. 21). O autor destaca, ainda que:

Toda criação de objetos responde a condições sociais e técnicas presentes num dado momento histórico. Sua reprodução também obedece a condições sociais. [...] A ação é o próprio homem. Só o homem tem ação, porque só ele 
tem objetivo, finalidade. A natureza não tem ação porque ela é cega, não tem futuro. As ações humanas não se restringem aos indivíduos, incluindo, também, as empresas, as instituições. [...] As ações resultam de necessidades, naturais ou criadas. Essas necessidades: materiais, imateriais, econômicas, sociais, culturais, morais, afetivas, é que conduzem os homens a agir e levam a funções. Essas funções de uma forma ou de outra vão desembocar nos objetos (SANTOS, 2014, p. 68 e 82).

A dinâmica social dá vida ao espaço, e aqui cabe ressaltar a compreensão de Lefebvre (2000) que o espaço é produto social, uma vez que a sociedade e suas relações implicam na mudança espacial. A definição de espaço está ligada a relação sociedade-natureza, pela dinamicidade daquela relacionado a esta, e não a junção como uma mistura inerte (SANTOS, 1988). No que diz respeito à compreensão do espaço e sua distinção da paisagem, esse autor traz a seguinte contribuição:

Paisagem e espaço não são sinônimos. A paisagem é o conjunto de formas que, num dado momento, exprimem as heranças que representam as sucessivas relações localizadas entre homem e natureza. O espaço são essas formas mais a vida que as anima (SANTOS, 2014, p. 103).

Acrescenta ainda que:

O espaço é a sociedade, e a paisagem também o é. [...] a paisagem existe através de suas formas, criadas em momentos históricos diferentes, porém coexistindo no momento atual. No espaço, as formas de que se compõe a paisagem preenchem, no momento atual, uma função atual, como resposta às necessidades atuais da sociedade. Tais formas nasceram sob diferentes necessidades, emanaram de sociedades sucessivas, mas só as formas mais recentes correspondem a determinações da sociedade atual (SANTOS, 2014, p. 104).

Para o autor, a paisagem é a materialidade, é a forma. Mas, o espaço na sua amplitude consegue mostrar a leitura dos objetos postos, da vida que os anima e que os fizeram existir pelas próprias necessidades criadas pela sociedade. "Enquanto simples materialidade, nenhuma parte da paisagem tem, em si, condições de provocar mudanças no conjunto. [...] A paisagem é história congelada, mas participa da história viva. São as suas formas que realizam, no espaço, as funções sociais" (SANTOS, 2014, p. 107).

Por conseguinte, as diferentes formas de paisagem encontradas em uma cidade realizam as diversas funções sociais que lhe são peculiares, essas funções são a dinâmica que somada à materialidade da paisagem definem o espaço, segundo o argumento desenvolvido pelo autor. No espaço estão às ideias associadas à materialidade, as formas materializadas 
pelas edificações. Nesse sentido, a exploração e o consequente uso de minerais provocam a materialização das formas de cada paisagem.

O movimento da reprodução da vida e das relações sociais, políticas e econômicas estabelecidas entre a dinâmica da exploração mineral e questões socioambientais envolvidas, podem ser entendidas como espaço, conforme Santos (2014). Daí depreende-se a necessidade de estudar a produção do espaço geográfico, pela categoria paisagem para analisar questões socioambientais da exploração mineral no município de Vitória da Conquista-BA.

As relações sociais estabelecidas nos diversos lugares, mediante as diferentes manifestações culturais imprimem sua marca no espaço, na qualidade de produto social. Porquanto, toda paisagem é sempre natural e social, além de ser composta por uma complexidade de elementos responsáveis pelo constante processo histórico de transformação. Por isso, é necessário compreender a sua complexidade, visto que é "subjetiva e objetiva, espacial e temporal, produção material e cultural, real e simbólica [...] dada pela forma, estrutura e funcionalidade” (MARTINELLI; PEDROTTI, 2001, p. 41). Para Cosgrove (2002), “a paisagem não está acabada, mas é percebida como um processo contínuo, cuja natureza se produz e se consome enquanto processo, cujos significados se naturalizam na paisagem, pela visão" (tradução nossa) ${ }^{3}$.

Ainda segundo esse autor, a paisagem não pode estar atrelada a visão fisiológica apenas, tendo em vista que existem sujeitos que possuem esta deficiência biológica, no entanto conseguem perceber as paisagens a sua volta através de outros sentidos do seu corpo, que podem mostrar-se muito mais eficientes. E ainda assim, o autor refuta a ideia de paisagem como aquilo que o campo de visão pode perceber, no sentido de que o visto é construído desde a infância e, portanto, dotado de juízo de valores.

Essa compreensão é superficial e não dá conta de explicar os processos sociais que construíram aquela paisagem, chamado pelo autor de "aspectos culturales del acto de ver" (COSGROVE, 2002, p. 69). Os aspectos culturais do ato de ver significam que para uma mesma imagem de paisagem, cada sujeito social a verá de uma forma diferente, ou seja, o significado da imagem será de acordo com as convenções culturais a que esse sujeito social foi submetido. Cosgrove acrescenta:

\footnotetext{
${ }^{3}$ Trecho original - "El paisaje se percibe cada vez más como un proceso continuado más que como una forma terminada. En tanto en cuanto proceso, la naturaleza se produce y se consume y sus significados se naturalizan en el paisaje principalmente por medio de su relación con la visión como garante de la verdade" (COSGROVE, 2002, p. 78).
} 
É inegável que a visão é uma função fisiológica, que não está presente em todo mundo e que nas pessoas com acuidade visual normal, o uso desta função é aprendido. A atenção da criança no processo de estabelecer relações visuais e de dar nomes concretos a grupos de objetos percebidos, enquanto outros são ignorados, é constantemente dirigido. Estes grupos variam tanto culturalmente, quanto de acordo com as diferenças relacionadas com a biologia, como o sexo e a idade. A classe de desenho mais elementar nos obriga a reconhecer isso ao nos lembrarmos das limitações da visão aprendida, quando, por exemplo, se pede a um para que trace a linha de definição de um objeto percebido, ao invés de desenhar "aquilo que acredita ver". O uso do sentido da visão é composto tanto por imagens vistas no passado, por experiências individuais, recordações e intenções, como pelas formas físicas e pelos espaços materiais, ante nossos olhos. Se bem, é obvio, que grande parte da visão aprendida é pessoal, outra grande parte também é social, governada por convenções sobre o que se deve ver, quem deve ver, quando e em que contexto, sobre as associações e significados atribuídos a uma determinada cena e sobre suas propriedades formais e compositivas (COSGROVE, 2002, p. 69, tradução nossa ${ }^{4}$ ).

As diferentes formas de olhar a paisagem, não correspondem unicamente à formação cultural do sujeito social, como apontou o referido autor, mas, também, em função dos interesses individuais. Segundo Puntel (2007, p. 293), “a paisagem não tem existência própria”, existe a partir da percepção do homem, e aí cada um a perceberá de forma diferente, conforme seus interesses. A priori, Santos (1988) também compreende a paisagem como visual, mas deixa claro que essa definição é proposta de forma didática, ao facilitar o ponto de partida do desenvolvimento conceitual dessa categoria. Para esse autor

Tudo aquilo que nós vemos, o que nossa visão alcança, é a paisagem. Esta pode ser definida como o domínio do visível, aquilo que a vista abarca. Não é formada apenas de volumes, mas também de cores, movimentos, odores, sons, etc. [...] A dimensão da paisagem é a dimensão da percepção, o que chega aos sentidos. Por isso, o aparelho cognitivo tem importância crucial nessa apreensão, pelo fato de que toda nossa educação, formal ou informal, é feita de forma seletiva [...] A percepção é sempre um processo seletivo de apreensão. [...] Nossa tarefa é a de ultrapassar a paisagem como aspecto, para chegar ao seu significado. A percepção não é ainda o conhecimento, que depende de sua interpretação e esta será tanto mais válida quanto mais limitarmos o risco de tomar por verdadeiro o que é só aparência (SANTOS, 1988 , p. 21 e 22).

\footnotetext{
${ }^{4}$ Trecho original -"Si bien es innegable que la vista es una función fisiológica, que no está presente en todo el mundo y que ronda el en personas con agudeza visual normal, el uso de esta función es aprendido. La atención del niño en el proceso de establecer relaciones visuales y de dar nombres concretos a grupos de objetos percibidos mientras que se otros se ignoran está constantemente dirigida. Estos grupos varían tanto culturalmente como de acuerdo con diferencias relacionadas con la biología como son el sexo y la edad. La clase de dibujo más elemental nos obliga a reconocer esto al recordarnos las limitaciones de la visión aprendida, cuando, por ejemplo, se le pide a uno que trace la línea definitoria de un objeto percibido en lugar de dibujar «aquello que uno cree ver». El uso del sentido de la vista está conformado tanto por imágenes vistas en el pasado, por experiencias individuales, recuerdos e intenciones como por las formas físicas y los espacios materiales ante nuestros ojos. Si bien es obvio que gran parte de la visión aprendida es personal, otra gran parte también es social, gobernada por convenciones sobre lo que se debe ver, quién lo debe ver, cuándo y en qué contexto, sobre las asociaciones y significados atribuidos a una escena dada y sobre sus propiedades formales y compositiva." (COSGROVE, 2002, p. 69)
} 
Dessa forma, dentro daquilo que o autor expôs como espaço: as relações entre os objetos geográficos, naturais e sociais, a paisagem pode ser considerada como um recorte espacial baseado na maneira como Santos (1988) a define. Entretanto, não se pode reduzí-la ao visto como um retrato, já que, também é resultado da dinâmica social. É preciso conhecer os processos de formação da paisagem analisada e as relações envolvidas. Haja vista que, "uma paisagem é uma escrita sobre a outra, é um conjunto de objetos que têm idades diferentes, é uma herança de muitos diferentes momentos" (SANTOS, 1988, p. 23).

As relações sociais estabelecidas nos diversos lugares, mediante as diferentes manifestações culturais imprimem sua marca no espaço, como produto social, percebida na paisagem. Nesse sentido, Puntel (2007, p. 288 e 291) afirma que "toda paisagem apresenta característica própria, tem forma e marca que resultam da interação da sociedade com a natureza" e "está em constante mutação". A primeira percepção da realidade se dá pela visão do que está aparente, mas não se pode negar que a aparência é resultado de processos construtivos e produtivos do espaço, dotados de interesses sociopolítico e econômico, e também, da própria dinâmica natural. Sobre a complexidade do estudo da paisagem na ciência Geográfica, Puntel (2007) destaca que:

[...] são muitas as dimensões de análise, e que estudar o espaço geográfico, tendo como ponto de partida a paisagem, é muito mais complexo do que normalmente o senso comum considera. É necessário, contudo, que o estudo da paisagem seja profundo e contemple o maior número possível de elementos que a formaram e são responsáveis pelas constantes transformações e pela dinamicidade das mesmas. Ao contemplar o estudo do espaço geográfico, tendo como conceito-chave a paisagem, faz-se necessário levar em consideração a dimensão objetiva e subjetiva da paisagem e o seu processo de construção e reconstrução que são permanentes (PUNTEL, 2007, p. 289).

A autora considera que a paisagem é construída e reconstruída continuamente e possui duas dimensões dentro do estudo do espaço geográfico: objetiva e subjetiva. Por conseguinte, é possível pesar que essa categoria de análise assim como o espaço é produto social e por isso ambos são produzidos e reproduzidos constantemente. Ora, a paisagem não é o espaço, conceitualmente, mas é possível considerar como parte dele, uma vez que sua análise se dá pela compreensão dos processos históricos de formação da mesma: naturais e sociais. Todavia, não deve ser considerada, meramente, como natural ou social; são dois aspectos que se complementam e devem ser analisados conjuntamente. Nesse sentido Lima afirma 
[...] as paisagens representam os aspectos naturais e sociais, cujas configurações em cada contexto histórico têm significação espacial e do acúmulo dos tempos pretéritos, e se apresenta como algo material, dotado também de subjetividades e impregnado de elementos culturais e simbólicos (LIMA, 2012, p.47).

Não é estanque, mas sim dinâmica e complexa, se produz e reproduz constantemente, de acordo com as relações sociais e seus interesses; é, também, produto social, contida no espaço. Nesse sentido, Santos (1988) corrobora que

\begin{abstract}
Não há, na verdade, paisagem parada, inerte, e se usamos este conceito é apenas como recurso analítico. A paisagem é materialidade, formada por objetos materiais e não-materiais [...] a materialidade construída vai ser fonte de relações sociais, que também se dão por intermédio dos objetos. Estes podem ser sujeitos de diferentes relações sociais - uma mesma rua pode servir a funções diferentes em distintos momentos. A paisagem é diferente do espaço. A primeira é a materialização de um instante da sociedade. Seria, numa comparação ousada, a realidade de homens fixos, parados como numa fotografia. $\mathrm{O}$ espaço resulta do casamento da sociedade com a paisagem. $\mathrm{O}$ espaço contém o movimento. Por isso, paisagem e espaço são um par dialético. Complementam-se e se opõem. Um esforço analítico impõe que os separemos como categorias diferentes, se não queremos correr o risco de não reconhecer o movimento da sociedade (SANTOS, 1988, p. 25).
\end{abstract}

A categoria de análise, ora estudada, é resultado da dinâmica da reprodução da vida, dos sujeitos sociais que a compõem cotidianamente, de suas relações entre eles próprios e também entre a natureza: é composta das formas resultantes das relações sociais. Assim, ao entendê-la como tudo aquilo que a vista alcança, é um recorte-retrato do espaço geográfico, cuja compreensão e análise da realidade se desenrolam pela busca dos processos históricos de sua formação, do questionamento de como as relações se deram nesse ininterrupto processo de produção do espaço, de quais fatores culminaram naquela paisagem observada.

Nesse sentido, falar sobre exploração mineral sem questionar e analisar os processos que a envolvem, sejam eles naturais, sociais, econômicos e/ou materiais, é apenas falar sobre a retirada mecânica de minerais. Por esse ângulo, essa pesquisa se faz importante, pois permite a análise da paisagem minerada, que retrata um instante da sociedade, cujos processos e dinâmica produzem o espaço geográfico. Ou seja, o movimento da sociedade resulta no espaço e como não é possível visualizar todo o espaço, isso se dá por meio da paisagem.

Segundo Silva (2008, p. 165), a "paisagem é para a Geografia um instrumento que possibilita uma primeira análise do espaço geográfico e, ao observá-la, percebem-se algumas relações estabelecidas ao longo do tempo". Dessa forma, ao se observar uma paisagem atual, não se pode, jamais, esquecer que nela estão imbricadas marcas do passado e ao mesmo 
tempo, sucessivas mudanças relacionadas às atividades econômicas e culturais da sociedade.

Para Rodriguez et. al.

As paisagens atuais são não só, do fundamento natural, mas das múltiplas vias geralmente superpostas de impactos próprios de diferentes etapas. Desta forma, o enfoque antropogênico na análise da paisagem deve estar conjugado com uma visão holística, para esclarecer o complexo caráter das atividades humanas sobre esta (RODRIGUEZ, et. al., 2004, p.159).

Nesse sentido, a paisagem subjetiva pode ser cultural, resultado das ações da própria cultura; para Rodriguez e Silva (2002, p. 98) a paisagem cultural "representa a dimensão sócio-ecológica da paisagem. São os espaços geográficos que as sociedades transformam para produzir, habitar e sonhar. Concebida assim, a paisagem é a interface da Natureza com a sociedade". Ainda sobre a compreensão da paisagem, Bertrand, apresenta a seguinte definição:

A paisagem não é a simples adição de elementos geográficos disparatados. É, em uma determinada porção do espaço, o resultado da combinação dinâmica, portanto instável, de elementos físicos, biológicos e antrópicos que, reagindo dialeticamente uns sobre os outros, fazem da paisagem um conjunto único e indissociável, em perpétua evolução. A dialética tipoindivíduo é próprio fundamento do método de pesquisa. É preciso frisar bem que não se trata somente da paisagem "natural", mas da paisagem total integrando todas as implicações da ação antrópica (BERTRAND, 1972, p. 141).

Percebe-se, assim, que o autor não privilegia nem a esfera natural nem a social na definição do conceito de paisagem e demonstra certa facilidade em enxergar a paisagem de forma integrada, ao entender que sociedade e natureza estão relacionadas entre si e formam uma só entidade de um mesmo espaço geográfico. Assim, o objeto da Geografia Física "não se deve restringir à morfologia da paisagem e suas subdivisões, mas, de preferência, projetarse para o estudo de sua dinâmica, estrutura funcional, conexões, etc." (SOTCHAVA, 1977, p. $5)$.

Na compreensão do autor, a Geografia Física tem seu próprio objeto: os geossistemas, para os quais não é possível analisar apenas os componentes da natureza isoladamente, mas, suas conexões com os componentes sociais; de forma que os geossistemas estão imbricados na paisagem, ao integrar os sistemas ecológicos, biológicos e sociais, os quais possibilitam a explicação da realidade paisagística e dos processos ali imbuídos. Nesse sentido, Almeida e Tertuliano definem sistema como: 
[...] um conjunto de unidades com relações entre si. Essas unidades possuem propriedades comuns. O conjunto encontra-se organizado em virtude das inter-relações entre as unidades, e o seu grau de organização permite que assuma a função de um todo que é maior do que a soma de suas partes. Cada unidade tem seu estado controlado, condicionado ou dependente do estado das outras unidades. Os sistemas devem ter elementos ou unidades que são as suas partes componentes. Os elementos integrantes dos sistemas encontram-se inter-relacionados, um dependendo do outro, através das ligações que indicam os fluxos (ALMEIDA; TERTULIANO, 2004, p. 115).

Essas conexões "se introduzem numa complicada rede de organização, cujas malhas se estendem até às esferas econômica e social” (SOTCHAVA, 1977, p. 05), ao englobar aspectos físicos e sociais, o conceito de geossistema pode ser entendido "como formações naturais que se desenvolvem influenciados tanto por fenômenos naturais quanto econômicos e sociais, que alteram sua estrutura e peculiaridades espaciais" (LIMBERGER, 2006, p. 101). O que propicia o estudo das paisagens de forma integrada, pela percepção dos processos naturais ao longo de eras geológicas sobre o modelado do relevo, sem perder de vista os processos histórico-sociais que imprimiram suas marcas na paisagem, evidenciando a identidade da sociedade sobre a mesma.

A referida autora sublinha que os fenômenos que se apresentam no espaço devem ser analisados com abordagens integradoras, uma vez que as dinâmicas relacionais extrapolam limites físicos e territoriais, tecendo um emaranhado complexo. De maneira que a realidade não pode ser explicada por fatores isolados, ou seja, não há como compreender a natureza sem compreender a sociedade e vice-versa. Segundo Lima (2012, p. 44), a abordagem sistêmica possibilita o desvendar e a compreensão do "arranjo espacial fruto das relações entre os componentes naturais (litologia, relevo, hidrologia, solos e vegetação) e sociais (agricultura, pecuária, mineração, urbanização...), que se materializam em diferentes configurações de paisagens." Sobre o método adotado e o estudo da paisagem, Sanches (2009) acrescenta que:

As variações físicas internas da paisagem podem ser estudadas de acordo com métodos próprios de diferentes disciplinas [...], a análise interdisciplinar facilita uma melhor compreensão de suas funções e processos ecológicos. $\mathrm{O}$ estudo das interrelações e interações entre os elementos constitutivos da paisagem, permite o acesso a interpretações de sua dinâmica, exigindo para isso o estabelecimento de escalas temporais (SANCHES, 2009, p. 41, tradução nossa ${ }^{5}$.

\footnotetext{
5 Trecho original: “[...] Las variaçones fisicas internas del paisaje puenden ser estudiadas según métodos propios de diferentes disciplinas [...], el analisis interdisciplinario facilita uma mejor compreensión de sus funcione y procesos ecológicos. El estúdio de las interrelaciones e interracciones entre los elementos constitutivos del paisaje permite acceder a interpretacions de su dinâmica, requiriéndose para ello el estaelecimiento prévio de escalas temporales (SANCHES, 2009, p. 41). 
No estudo da paisagem é preciso compreender as relações sociais, ecológicas (clima, hidrologia, geomorfologia) e biológicas (vegetação, solo e fauna) que ocorrem entre os geossistemas, bem como as contradições existentes nessas relações. Uma vez que "os sistemas se encontram incorporados em conjuntos maiores, mantendo conexões de matéria e energia, que constituem o seu ambiente. [...] sempre estão funcionando perante flutuações de fornecimento de matéria e energia" (ALMEIDA; TERTULIANO, 2004, p. 115 e 118).

De forma simples, a teoria sistêmica, pode ser compreendida como um sistema de recebimento de matéria e energia, transformada e liberada. Assim, é possível depreender que por meio da força de trabalho imposta na exploração mineral, ocorre a entrada de matéria e energia no geossistema, cuja saída corresponde aos minerais explorados. As vias de entrada da mineração são os processos de exploração mineral e a rede de drenagem é a comercialização desses bens minerais; subsistemas que envolvem o ecológico, biológico e social, os quais de modo integrado propiciam transformações nas paisagens.

Decorrente dessa dinâmica espacial é preciso entender que a explicativa para as realidades vividas não é possível pelo estudo de fatores isolados, uma vez que, vários sistemas integram fenômenos em diferentes paisagens. No sentido dos sistemas integrados, Bertalanffy (2015) explica a Teoria Geral dos Sistemas e traz a seguinte contribuição:

Em resumo, aparecem "sistemas" de várias ordens, que não são inteligíveis mediante a investigação de suas respectivas partes isoladamente. Concepções e problemas desta natureza surgiram em todos os planos da ciência quer o objeto de estudo fossem coisas inanimadas quer fossem organismos vivos ou fenômenos sociais. [...] Parece existirem leis gerais dos sistemas que se aplicam a qualquer sistema de certo tipo, independentemente das propriedades particulares do sistema e dos elementos em questão. Estas considerações conduzem ao postulado de uma nova disciplina científica que chamamos Teoria Geral dos Sistemas. Seu objetivo é a formulação de princípios válidos para os "sistemas" em geral, qualquer que seja a natureza dos elementos que os compõe e as relações ou "forças" existentes entre eles. A Teoria Geral dos Sistemas, portanto, é uma ciência geral da "totalidade", que agora era considerada um conceito vago, nebuloso e semimetafísico. Em forma elaborada seria uma disciplina lógico-matemática, em si mesma puramente formal, mas aplicável às várias ciências empíricas (BERTALANFFY, 2015, p. 62).

A fim de explicar a integração sistêmica, Bertalanffy (2015) propôs a Teoria Geral dos Sistemas, ao mostrar sua aplicabilidade inicialmente nas ciências exatas (biologia/ física), e posteriormente desenvolve a aplicação dessa teoria nas ciências sociais, a que ele especifica para as relações dos grupos humanos, a própria sociedade. Segundo o autor, "[...] a ciência social é a ciência dos sistemas sociais. Por essa razão terá de usar o enfoque da ciência geral 
dos sistemas" (BERTALANFFY, 2015, p. 249). Propõe que se considere tal ciência em sentido amplo: abarca várias áreas do conhecimento; e por isso é possível realizar estudos sob essa concepção, também, na Geografia, uma vez que seu enfoque se dá no estudo da relação sociedade natureza, cujo produto é o espaço geográfico.

Para o autor, a aplicação prática da teoria dos sistemas aos problemas que surgem na sociedade, tais como, político, econômico, entre outros, “[...] mostra especialmente que o enfoque dos sistemas não se limita às entidades materiais em física, biologia e outras ciências naturais, mas é aplicável a entidades que são parcialmente imateriais e altamente heterogêneas" (BERTALANFFY, 2015, p. 251). Sobre a aplicabilidade da Teoria Sistêmica, o autor corrobora:

A ciência natural trata de entidades físicas no tempo e no espaço, partículas, átomos e moléculas, sistemas vivos em vários níveis, conforme o caso. A ciência social tem de tratar com seres humanos no universo da cultura criado por eles. O universo cultural é essencialmente um universo simbólico. Os animais estão envolvidos por um universo físico que têm de enfrentar, o meio físico, as presas a capturar, os predadores a evitar e assim por diante. $\mathrm{O}$ homem, ao contrário está envolvido por um universo de símbolos. Começando com a linguagem, que é um requisito da cultura, até as relações simbólicas com seus semelhantes, o estado social, leis, ciência, arte, moral, religião e inumeráveis outras coisas, o comportamento humano, exceto nos aspectos básicos das necessidades biológicas da fome e do sexo, é governado por entidades simbólicas. Podemos também dizer que o homem tem valores que são mais do que biológicos e transcendem a esfera do mundo físico. Estes valores culturais podem ser biologicamente sem importância ou mesmo deletérios (BERTALANFFY, 2015, p. 251/252).

A aplicação da teoria sistêmica às emergentes questões socioambientais é pertinente, pois integra os três subsistemas básicos ${ }^{6}$ que formam o geossistema. Evidenciam que os problemas ditos ambientais não envolvem, isoladamente, a dinâmica física, isto é, biológica e ecológica; pois aí o homem estaria excluído dos processos de produção do espaço, cuja dinâmica o produz: o espaço é o movimento. Entretanto, as questões ambientais devem ser consideradas e analisadas como socioambientais, uma vez que, o homem é um ser pertencente à natureza.

Nesse sentir, a análise de questões socioambientais que envolvem a exploração mineral deve partir de uma concepção integradora dos sistemas que envolvem essa dinâmica: os sistemas ecológicos, biológicos e sociais. Pois como enfatiza Sotchava (1977), “embora os

\footnotetext{
${ }^{6}$ Os três subsistemas dizem respeito a: 1- Potencial ecológico, formado por geomorfologia, clima e hidrografia; 2- Potencial biológico, formado por fauna, flora e solos e 3- A sociedade. De acordo com Christofoletti "O geossistema resultaria da combinação de um potencial ecológico (geomorfologia, clima, hidrologia), uma exploração biológica (vegetação, solo, fauna) e uma ação antrópica, não apresentando necessariamente, homogeneidade fisionômica, e sim um complexo essencialmente dinâmico" (CHRISTOFOLETTI, 1999, p. 42.)
} 
geossistemas sejam fenômenos naturais, todos os fatores econômicos e sociais, influenciando sua estrutura e peculiaridades espaciais, são tomados em consideração durante o seu estudo" (SOTCHAVA, 1977, p. 6). Nas palavras de Nascimento e Sampaio

A Teoria Geossistêmica é relativamente recente em Geografia; foi proposta na antiga União Soviética, na década de 1960, e primeiro mencionada pelo russo Sotchava, no início dessa década, como uma forma de estudo de paisagens geográficas completas, definida como uma unidade dinâmica com organização geográfica própria e um espaço que permite repartição de todos os componentes de um geossistema, o que assegura sua integridade funcional. [...] Os geossistemas, ratifique-se, são ambientes naturais, mas configuram-se com a interferência da sociedade humana, através dos fatores culturais, sociais e econômicos em geral (NASCIMENTO; SAMPAIO, 2005, p. 169-173).

Depreende-se que o diferencial dos geossistemas se encontra na integração da sociedade com os sistemas ecológicos e biológicos, cujos processos ao longo do tempo materializaram a paisagem em diferentes perspectivas. Para Bernardes e Ferreira (2005) "o discurso ecológico está cheio de contradições e é altamente diversificado" (BERNARDES; FERREIRA, 2005, p. 34), e nesse sentido a busca pela explicativa da realidade ambiental no quesito exploração mineral e as questões socioambientais envolvidas não se devem pautar no discurso ecológico apenas, pois dentro da teoria sistêmica e pela compreensão do conceito de geossistema, o aspecto ecológico é associado ao aspecto biológico e social.

Portanto, compreender a relação sociedade-natureza nos processos da exploração mineral, bem como questões socioambientais que envolvem essa atividade econômica, é imprescindível a compreensão da análise integrada das paisagens que compreendem essa complexa teia.

\section{A relação sociedade-natureza no processo da exploração mineral}

A cidade como construção humana, envolvida pela diferença de classes do sistema capitalista de produção, convive com diversificados impasses socioambientais decorrentes dos interesses e formas de apropriação em cada parte da cidade. No que diz respeito à utilização dos recursos naturais como elemento indispensável para a materialização da cidade, é explícito a transformação da natureza em mercadoria. Nas palavras de Bernardes e Ferreira:

A compreensão tradicional das relações entre a sociedade e a natureza desenvolvidas até o século XIX, vinculadas ao processo de produção capitalista, considerava o homem e a natureza como pólos excludentes, 
tendo subjacente a concepção de uma natureza objeto, fonte ilimitada de recursos à disposição do homem. Com base nessa concepção, desenvolveram-se práticas, por meio de um processo de industrialização, em que a acumulação se realizava por meio da exploração intensa dos recursos naturais, com efeitos perversos para a natureza e os homens (BERNARDES; FERREIRA, 2005, p. 17).

Os autores fazem a sua colocação no tempo verbal passado, mas é importante salientar que no presente a relação sociedade-natureza continua a ser excludente. Em que o homem a domina e explora como fonte de recursos a ser transformada em mercadoria. Decorre que, pela não compreensão do homem como integrante da natureza e ao utilizar-se dos recursos naturais para atender as necessidades criadas por ele, a cidade é afetada por problemas socioambientais.

A julgar porque os problemas ambientais não existem isoladamente, mas estão imbricados nos reveses sociais, pois "a apropriação da natureza pelo indivíduo está sempre inserida numa determinada forma social” (BERNARDES; FERREIRA, 2005, p. 19). Por isso, a necessidade da discussão da questão socioambiental frente a relação sociedade-natureza diante do contínuo processo de produção do espaço geográfico.

Todavia, por meio da Ciência Geográfica, não é possível compreender a relação sociedade-natureza de forma excludente e dicotomizada, pois o homem é antes de tudo um ser biológico, parte integrante da natureza: na medida em que a transforma, é, também, transformado, como relação consequente. Porém, ao se desenvolver e ao ser construído socialmente, incorpora aspectos de sua cultura, dos conhecimentos que lhe são transmitidos, e admite a ideia de externo a natureza, como seu agente dominador.

A exploração e comercialização mineral demonstram a apropriação da natureza como mercadoria, na medida em que é atribuído valor de troca aos minerais, o que fomenta o processo produtivo, em busca de lucros cada vez mais altos. Entretanto, o processo de produção mineral deixa marcas negativas na paisagem, as quais são difíceis de recuperar e podem resultar em impasses socioambientais entre empresários mineiros, comunidades vizinhas às áreas de exploração mineral e o poder público local.

Tal como o espaço é produzido por todos e sua apropriação é desigual, por causa das relações contraditórias que se estabelecem nele, assim o é nas áreas de exploração mineral. Cuja produção espacial é contínua e se dá por todos os sujeitos envolvidos nesse processo produtivo da exploração mineral, mas a entrega do passivo ambiental é diferenciada. Desse modo, os causadores deixam aquelas áreas inservíveis para a comunidade local, numa terra 
em que as formas de uso do solo passam a ser ineficientes e/ou inexistentes, diante da intensa degradação ali observada.

Bernardes e Ferreira (2005) chamam a atenção para a necessidade de pensar e discutir os problemas ambientais levando-se em consideração que os mais diversos processos que os ocasionam são determinados pelas relações contraditórias que se estabelecem no processo de produção do espaço geográfico. Então, para buscar compreensão sobre questões socioambientais que envolvem a atividade mineral no município, é preciso discutir a paisagem e as relações contraditórias aí estabelecidas.

No município de Vitória da Conquista-BA, é notável uma movimentação significativa no seu espaço geográfico, tanto na área urbana, quanto na rural, expresso em suas paisagens. O espaço rural conquistense tem sido produzido, entre outros elementos, pela exploração de diversos minerais. A mineração é considerada como uma das atividades econômicas mais importantes do Brasil (BARRETO, 2001), apesar dos impactos socioambientais serem, em sua maioria, negativos não se pode omitir aqueles de classificação positiva. Esta expressiva formação mineral ocorre porque "a maior parte do município está localizada no ambiente denominado Planalto da Conquista que apresenta uma estrutura geológica composta, parcialmente, por rochas cristalinas" (MAIA, 2005, p. 69).

Paralelo à exploração mineral, o espaço urbano é constantemente produzido e reproduzido, principalmente através da materialização das edificações, através da indústria da construção civil. Essa indústria utiliza, dentre muitos outros materiais, os minerais de uso imediato na construção civil, que são explorados nesse município. Vale ressaltar que a localização das áreas de exploração desses recursos naturais, próximo aos consumidores finais reduz o custo dos mesmos, sendo esse um dos fatores positivos.

Assim, é possível depreender, que ao mesmo tempo em que Vitória da Conquista é uma cidade em pleno crescimento urbano é, também, um município com exploração mineral em ascensão. Porém, esta atividade precisa ser desenvolvida, pautada pela Legislação ambiental e mineral pertinentes a cada caso específico, colaborando para que os impactos negativos ocasionados por essa atividade sejam minimizados e as comunidades locais sejam resguardadas e respeitadas diante de seus atributos culturais e da reprodução da vida.

Sobre a integração dos sistemas em diferentes escalas, a Ciência Geográfica, por meio do método sistêmico consegue explicar a realidade por compreender a produção e organização do espaço pelos processos que envolvem os geossistemas, compreendendo assim a relação sociedade-natureza de maneira integrada. Uma vez que os problemas ditos 
ambientais, não existem em si só e apenas, eles resultam de questões sociais, principalmente, consequentes do sistema capitalista dentro da sociedade de consumo, que considera o homem como ser externo e dominante da natureza.

\section{Considerações finais}

A paisagem é resultado da interação da sociedade com a natureza ao longo do tempo, como produto social carrega marcas de processos históricos, sociais, econômicos e políticos nos processos físicos, geológicos, ecológicos e biológicos. De modo que a formação física de determinada paisagem traz consigo eras geológicas, que agregam clima, vegetação, hidrografia e solos no modelado do relevo. São processos físicos ao longo de um tempo, que implicam na formação geológica, bem como na ocorrência de minerais no subsolo em locais que abrigam jazidas específicas.

As relações sociais estabelecidas no espaço geográfico imprimem suas marcas na paisagem natural. Assim os processos sociais, econômicos e políticos estão envolvidos no movimento da sociedade no processo de produção e reprodução do espaço, por meio das materializações de suas formas. A exploração mineral é uma atividade econômica importante para a sociedade, está envolvida por diferentes interesses e percepções de acordo com os sujeitos sociais que estão envolvidos.

Em uma relação dicotômica entre a sociedade e a natureza, esta é percebida como fonte de recursos para atender as demandas e necessidades criadas pela sociedade, de modo que a natureza é posta como mercadoria, vez que é atribuído valor de troca aos seus recursos naturais. Os minerais explorados são mercadorias e envolvem uma cadeia produtiva com significativo valor comercial. Assim, contraditoriamente a exploração mineral é necessária e conflituosa no que diz respeito as questões socioambientais que a envolvem.

A mineração influencia diretamente a dinâmica da paisagem, pois os processos físicos são diretamente influenciados pelos processos mecânicos para a retirada dos minerais do subsolo. De forma que estudar uma paisagem minerada apenas sob a ótica da mecanização de retirada de minerais não explica os processos sociopolíticoeconômicos que permeiam essa atividade econômica e propicia a compreensão da dinâmica da paisagem minerada, sob a perspectiva socioambiental. 


\section{Referências}

ALMEIDA, J. R.; TERTULIANO, M. F.. Diagnose dos sistemas ambientais: métodos e indicadores. In: Avaliação e Perícia Ambiental. Cunha, S. B. da; Guerra, A. J. T. (Orgs.). Rio de Janeiro: Bertrand Brasil, 2004. P. 115-170

BARRETO, M. L. (orgs.). Mineração e desenvolvimento sustentável: desafios para o Brasil. Rio de Janeiro: CETEM/MCT, 2001. 215 p.

BERNARDES, Júlia Adão; FERREIRA, Francisco Pontes de Miranda. Sociedade e Natureza. In: CUNHA, Sandra Baptista da Cunha; GUERRA, Antônio José Teixeira (Orgs.). A questão ambiental: diferentes abordagens. 2. ed. Rio de Janeiro: Bertrand Brasil, 2005.

BERTALANFFY, Ludwig von. Teoria Geral dos Sistemas: fundamentos, desenvolvimento e aplicações. 8 ed. Petrópolis: Vozes, 2015. Tradução Francisco M. Guimarães.

ERTRAND, G. Paisagem e Geografia Física Global: Esboço Metodológico. Cadernos de Ciências da Terra do Instituto de Geografia da USP, São Paulo, n. 13, 1972. Tradução Olga Cruz.

CHRISTOFOLETTI, Antonio. Modelagem de Sistemas Ambientais. São Paulo: Edgard Blücher, 1. ed. 1999.

Aplicação da abordagem em sistemas na Geografia Física. Revista Brasileira de Geografia. São Paulo: n. 2, p. 21-33, 1990.

COSGROVE, Denis. Observando la naturaleza: el paisaje y el sentido europeo de la vista. Boletín de la A.G.E. Universidad de California, Los Angeles, n. 34, págs. 63-89, 2002 < http://age.ieg.csic.es/boletin/34/3406.pdf> Acesso em 07/05/2009.

HARVEY, David. A Justiça Social e a Cidade. Editora HUCITEC. São Paulo, 1980. Tradução de Armando Corrêa da Silva.

LEFEBVRE, Henri. A produção do espaço. Trad. Doralice Barros Pereira e Sérgio Martins (do original: La production de l'espace. 4e éd. Paris: Éditions Anthropos, 2000). Primeira versão: início - fev.2006

LIMA, E. M. Interações Socioambientais na Bacia Hidrográfica do Rio Catolé - Bahia. 2012. Tese (Doutorado em Geografia)-Universidade Federal de Sergipe,2012.

LIMBERGER, Leila. Abordagem sistêmica e complexidade na geografia. Geografia, Rio Claro, v. 15, n. 2, p. 95-109, 2006. Disponível em: < http://www.uel.br/revistas/geografia $>$. Acesso em: 22 dez. 2016.

MAIA, Meirilane Rodrigues. Zoneamento geoambiental do município de Vitória da Conquista-BA: um subsídio ao planejamento. 2005. 170 f. Dissertação (Mestrado em Geografia) - Instituto de Geociências, Universidade Federal da Bahia, Salvador 
MARTINELLI, Marcelo; PEDROTTI, Franco. A cartografia das unidades de paisagem: questões metodológicas. Revista do departamento de Geografia, São Paulo, v. 14, p. 39-46, 2001

NASCIMENTO, Flávio Rodrigues do; SAMPAIO, José Levi Furtado. Geografia Física, Geossistemas e Estudos integrados da paisagem. Revista da Casa da Geografia de Sobral, Sobral, v. 6/7, n. 1, p. 167-179, 2004/2005.

PUNTEL, Geovane Aparecida. A paisagem no ensino da Geografia. Ágora, Santa Cruz do Sul, v. 13, n. 1, p. 283-298, jan./jun. 2007.

RODRIGUEZ, José Manuel Mateo; SILVA, Edson Vicente da. A classificação das paisagens a partir de uma visão geossistêmica. Mercator - Revista de Geografia da UFC, Fortaleza, ano 01, n. 01, p. 95-112, 2002.

RODRIGUEZ, J. M. M.; SILVA, E. V. da; CAVALCANTI, A. P. B. Geoecologia das paisagens: uma visão geossistêmica da análise ambiental. Fortaleza: Editora UFC, 2004.

SANCHES, Roberto. Ordenamiento territorial: Bases y Estrategia Metodológica para la Ordenación de Tierras. 1ª . ed. Buenos Aires: Orientación Gráfica Editora, 2009. 266p.

SANTOS, Milton. Metamorfoses do Espaço Habitado, Fundamentos Teórico e Metodológico da Geografia. Hucitec.São Paulo 1988.

A natureza do Espaço: Técnica e Tempo, Razão e Emoção. EDUSP: São Paulo, 2014. 4. ed. 8. Reimpr.

SILVA, Márcio Luiz da. Paisagem e Geossistema: contexto histórico e abordagem teórico metodológica. Geoambiente on-line Revista Eletrônica do Curso de Geografia do Campus Jataí - UFG, Jataí, n. 11, p. 163-185, jul-dez 2008.

SMITH, Neil. Desenvolvimento desigual. Rio de Janeiro: Bertrand Brasil, 1988.

SOTCHAVA, V. B. Introdución a la teoria de los geossistemas. Novo Sibersk: Nauka, 1963. $318 \mathrm{p}$.

1977.

O estudo dos geossistemas. Métodos em questão. São Paulo: $n^{\circ}$ 16, IGEOG - USP, 